\title{
THE RELATIONSHIP BETWEEN ACCELERATED MIGRATION TIME IN ACMT AND PONDING TIME IN PONDING TEST FOR CEMENT-BASED MATERIALS
}

\author{
Yu-Sheng Chen \\ Department of Civil Engineering, National Taiwan University, Taipei, Taiwan \\ Ming-Chih Li \\ Department of Civil Engineering, National Taiwan University, Taipei, Taiwan \\ Yi-Wen Chan \\ Department of Civil Engineering, National Taiwan University, Taipei, Taiwan \\ Chung-Chia Yang \\ Institute of Materials Engineering, National Taiwan Ocean University, Keelung, Taiwan., ccyang@mail.ntou.edu.tw
}

Follow this and additional works at: https://jmstt.ntou.edu.tw/journal

Part of the Civil and Environmental Engineering Commons

\author{
Recommended Citation \\ Chen, Yu-Sheng; Li, Ming-Chih; Chan, Yi-Wen; and Yang, Chung-Chia (2012) "THE RELATIONSHIP BETWEEN \\ ACCELERATED MIGRATION TIME IN ACMT AND PONDING TIME IN PONDING TEST FOR CEMENT-BASED \\ MATERIALS," Journal of Marine Science and Technology. Vol. 20: Iss. 1, Article 1. \\ DOI: $10.51400 / 2709-6998.2416$ \\ Available at: https://jmstt.ntou.edu.tw/journal/vol20/iss1/1 \\ This Research Article is brought to you for free and open access by Journal of Marine Science and Technology. It has been \\ accepted for inclusion in Journal of Marine Science and Technology by an authorized editor of Journal of Marine Science and \\ Technology.
}


THE RELATIONSHIP BETWEEN ACCELERATED MIGRATION TIME IN ACMT AND PONDING TIME IN PONDING TEST FOR CEMENT-BASED MATERIALS

Acknowledgements

The financial support of National Science Council, ROC, under the grant NSC 96-2628-E-019-029-MY3 and NSC 98-2221-E-019-048-MY3 is gratefully appreciated. 


\title{
THE RELATIONSHIP BETWEEN ACCELERATED MIGRATION TIME IN ACMT AND PONDING TIME IN PONDING TEST FOR CEMENT-BASED MATERIALS
}

\author{
Yu-Sheng Chen ${ }^{1}$, Ming-Chih $\mathrm{Li}^{1}$, Yi-Wen Chan ${ }^{1}$, and Chung-Chia Yang ${ }^{2}$
}

Key words: ACMT, chloride profile, ponding test, total amount of chloride.

\begin{abstract}
The salt ponding test has been widely used in recent year to evaluate the durability of cement-based materials. However, the duration of more than 90 days salt ponding is considered as time-consuming. In this study, the electrochemical technique (ACMT; Accelerated Chloride Migration Test) is applied to accelerate the movement of chloride ion in the cement-based materials to reduce the duration of testing time. The chloride profiles are obtained from ponding test with various ponding times and ACMT with different accelerated migration times. The total amount of chloride in specimens are calculated from the profiles and compared. Based on the total amount of chloride, the equivalent accelerated chloride migration time to the ponding time is obtained. The experimental result shows that the total amount of chloride for the 9-, 10-, 11-, and 12-h accelerated migration time in ACMT is close to the 60-, 90-, 120-, and 150-days ponding time in ponding test, respectively.
\end{abstract}

\section{INTRODUCTION}

Chloride-induced corrosion is one of the major causes affecting the corrosion of reinforcement in concrete. Since the rate of penetration of the chloride into concrete is very slow, it is important to find a simple and short test to assess the resistance of concrete to chloride penetration.

The salt ponding test (ASTM C1543) is a common method for measuring the penetration of chloride into concrete. For the salt ponding test, chloride ions require considerable time

Paper submitted 02/04/10; revised 06/05/10; accepted 06/10/10. Author for correspondence: Chung-Chia Yang (e-mail: ccyang@mail.ntou.edu.tw).

${ }^{I}$ Department of Civil Engineering, National Taiwan University, Taipei, Taiwan.

${ }^{2}$ Institute of Materials Engineering, National Taiwan Ocean University, Keelung, Taiwan. to penetrate the concrete specimen. Therefore, several accelerated chloride ions diffusion test methods by the application of an electrical field were developed to accelerate the movement of chloride ions. Whiting [9] developed the rapid chloride permeability test (RCPT) procedure. A $60-\mathrm{V}$ power source is applied to accelerate the movement of chloride ions, and the total charge passed is used to assess the concrete durability. Andrade and Whiting [2] obtained the diffusion coefficients from the ponding test and after the RCPT (ASTM C1202). They reported that the diffusion coefficients from the ponding test are greater than from the RCPT, and it was suggested to reduce the voltage drop and increase the test period in RCPT. McGrath and Hooton [6] found that there is a poor correlation between the results of charge passed from RCPT and diffusion characters from ponding test when the standard tests were conducted and the ponding data was analyzed in the conventional manner.

In the past, a conventional diffusion method was often conducted to evaluate the chloride diffusion characteristic of cement-based materials by using the steady-state chloride flow across the specimen $[3,5,7]$. However, the conventional diffusion method requires considerable time to obtain the steadystate chloride flow across the specimen and need sampling and analyzing chlorides during the tests. The disadvantages of conventional diffusion test are time-consuming, laborious and expensive. The accelerated chloride migration test (ACMT) for accelerated chloride migration has been proposed by applying an electrical field to accelerate the ingress of chloride ions [10, 11, 13]. Using ACMT, Yang and Cho [13] obtained a correlation between the chloride migration rate and the electrical current measured at a given charge passed in steady state. Yang and Chiang [11] presents a simplified procedure for measuring the steady state chloride migration coefficient in concrete using the ACMT.

The objective of this work is to determine if there exist a direct relationship between the duration of ponding test and the accelerated migration time of ACMT. The total amount of chloride determined from chloride profile in ponding test and ACMT are used to obtain the relation ship between ponding time and migration time. 
Table 1. Mix proportions of mortar.

\begin{tabular}{|c|c|c|c|c|c|c|}
\hline \multirow[b]{2}{*}{ Mix } & \multirow[b]{2}{*}{$\mathrm{w} / \mathrm{c}$} & \multicolumn{4}{|c|}{ Unit content: $\mathrm{kg} / \mathrm{m}^{3}$} & \multirow{2}{*}{$\begin{array}{c}28 \text { day } \\
\text { Compressive } \\
\text { strength }(\mathrm{MPa})\end{array}$} \\
\hline & & Water & Cement & $\begin{array}{c}\text { Fine } \\
\text { aggregate }\end{array}$ & S. P. & \\
\hline M35 & 0.35 & 241.9 & 721.9 & 1380.1 & 3.6 & 56.4 \\
\hline M45 & 0.45 & 278.0 & 625.0 & 1380.1 & 0 & 40.4 \\
\hline M55 & 0.55 & 303.1 & 551.1 & 1380.1 & 0 & 32.9 \\
\hline M65 & 0.65 & 321.2 & 494.1 & 1380.1 & 0 & 27.4 \\
\hline
\end{tabular}

\section{EXPERIMENTAL PROGRAM}

\section{Materials and Specimen Preparation}

In this investigation, four kinds of mortar with water to cement ratios ranging from 0.35 to 0.65 were used. ASTM Type I Portland cement and river sand were used as binder and fine aggregate, respectively. Details of the mix proportions for the mortar mixes and the compressive strength are summarized in Table 1. For all mixes, the amount of fine aggregate was kept constant as $1380.1 \mathrm{~kg} / \mathrm{m}^{3}$. A superplasticizer (sulfonated naphthalene formaldehyde condensates) was used for mortar containing a low w/c ratio such as 0.35 .

Cylinders, each $100 \mathrm{~mm}$ in diameter and $200 \mathrm{~mm}$ in height, were cast. After the mortar cylinders were taken out of the molds, they were cure in water at $23^{\circ} \mathrm{C}$ for 91 days. The specimens of $50 \mathrm{~mm}$-thick slices for the ponding and the ACMT tests were cut from the mid-portion of the cylinders.

\section{Experimental Procedure}

Two experimental arrangements were used to study the transport properties of mortar and the results of transport properties were compared. One is the accelerated chloride migration test (ACMT), and the other one is salt ponding test.

\section{1) Accelerated Chloride Migration Test (ACMT)}

The electrochemical technique is applied to accelerate the migration of chloride ions in mortar to estimate the transport properties of mortar. Before test, the specimens were water-saturated under vacuum following the specification in ASTM C1202. The lateral surface of specimen was coated with epoxy and the specimen was placed in the vacuum desiccator, the pressure less than $1 \mathrm{mmHg}$ (133 MPa) was maintained for 3 hours. De-aerated water was added to immerse the specimen and the vacuum level was maintained for one additional hour. Specimen was soaked in the added water for 18 hours after turning off the pump. Then the specimen was removed from water, and placed in the ACMT setup. A schematic presentation of accelerated chloride migration test (ACMT) set-up is illustrated in Fig. 1 [12]. The specimen was placed between two acrylic cells. The anodic cell was filled with 4.5 liter of 0.3 mole/ $\mathrm{L} \mathrm{NaOH}$ solution (anodic solution) and the cathodic cell with 4.5 liter of 0.52 mole/ $\mathrm{L} \mathrm{NaCl}$ solution (cathodic solution). Two mesh electrodes $(10 \mathrm{~cm} \mathrm{di-}$ ameter, \#20 mesh brass screen) were placed on two sides of the $50 \mathrm{~mm}$-thick specimen in such a way that the electrical

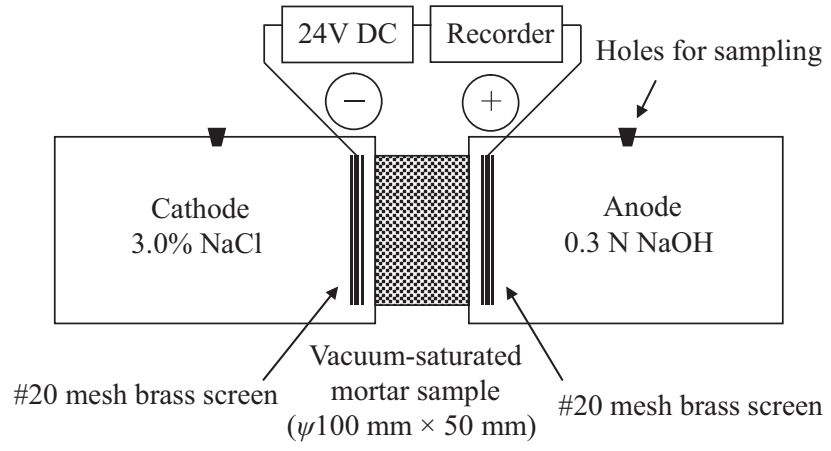

Fig. 1. Schematic diagram of accelerated chloride migration test (ACMT).

field is applied primarily across the test specimen. The cells were connected to a $24-\mathrm{V}$ power source. The cathode is connected to the negative pole and the anode is connected to the positive pole of the power supply.

In this investigation, two experimental procedures were carried out for chloride analysis. One of the procedures is measure the quantity of chloride ions passing through the specimen in anode cell and determined periodically using potentiometric titration with $0.01 \mathrm{~N}$ silver nitrate $\left(\mathrm{AgNO}_{3}\right)$ solution for quantitative analysis. Three of the specimens for each mixes were tested for determining the breakthrough time $\left(t_{b}\right)$ from the chloride concentration-time curve. The other procedure is measure the chloride penetration profile of specimen in non-steady state stage. Five different accelerated migration times less than the breakthrough time $\left(t_{b}\right)$ of each mixes on a potential difference of 24 volt in Table 2 were used. After the test of ACMT, the specimen was taken out from the acrylic cells. The surface of each specimen was brushed by using wire brushed to avoid the adhesion of salt crystal on the exposed chloride surface. Fig. 2 shows that three cuboid specimens $(2 \mathrm{~cm} \times 2 \mathrm{~cm} \times 5 \mathrm{~cm})$ were obtained by cutting from the ACMT specimen $(\varphi 10 \mathrm{~cm} \times 5 \mathrm{~cm})$, and each cuboid specimen was dry cut from the exposed chloride surface for every approximately $5-\mathrm{mm}$. The slice specimens were then dried at $105^{\circ} \mathrm{C}$ to constant mass and grounded to pass through a $300-\mu \mathrm{m}$ sieve. According to the specification in AASHTO T260, the total chloride content of the powder sample was analyzed. A 3-g powder sample was weighted and digested using concentrated $\mathrm{HNO}_{3}$ solution. The acid solution was heated to boiling on a hot plate and boiled for about $1 \mathrm{~min}$ and then left to cool. The cooled samples were filtered through double filter paper (Whatman No. 41 over No. 40 filter paper), the residue being washed with boiling distilled water. Filtrate and washings were made up about 125 to $150 \mathrm{ml}$ with distilled water. The sample of filtrate was analyzed using potentiometric titration with $0.01 \mathrm{~N}$ silver nitrate $\left(\mathrm{AgNO}_{3}\right)$ solution for quantitative analysis.

\section{2) Salt Ponding Test}

In this study, the ponding test similar to the test described in ASTM C1543 was used. Before the test, specimens were 
Table 2. The breakthrough time and the accelerated migration time in ACMT.

\begin{tabular}{ccc}
\hline Mix & $t_{b}(\mathrm{~h})$ & Accelerated migration time $(\mathrm{h})$ \\
\hline M35 & 73.1 & $12,24,48,72$ \\
M45 & 41.0 & $6,12,24,36$ \\
M55 & 29.8 & $6,12,18,24$ \\
M65 & 20.7 & $3,6,12,18$ \\
\hline
\end{tabular}

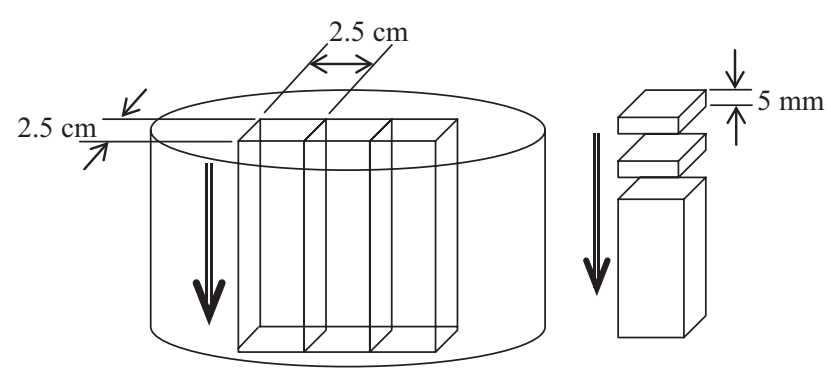

Fig. 2. An illustration of slice cutting from ACMT and ponding specimens.

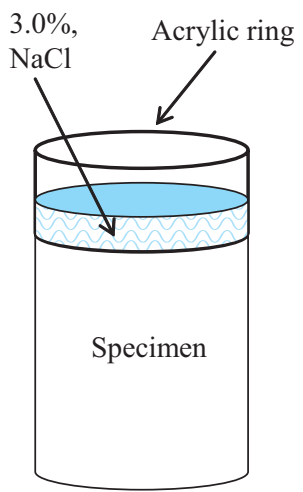

Fig. 3. Experimental arrangement used in ponding test.

air-dried, and then the lateral surface of specimens was coated with epoxy that was allowed to harden for up to $24 \mathrm{~h}$. The specimens were sealed around the outside edge using the acrylic ring to create the dam for chloride solution (Fig. 3). The specimens with dams were subjected to continuous ponding with $3.0 \% \mathrm{NaCl}$ solutions to a depth of $15 \mathrm{~mm}$ for 60,90 , 120, and 150 days. The top of acrylic ring was sealed with plastic wrap to minimize evaporation, and additional solution was added if necessary to maintain the $15 \mathrm{~mm}$ depth. After ponding, the solution was removed and the specimens were allowed to dry. And then the chloride penetration profile of specimens was obtained from the same procedure as ACMT.

Following the EGC is the frame synchronization which is attained by correlation filtering. The timing synchronization block performs the spreading code acquisition and tracking. The code acquisition is conducted by convolving the received signal with a correlation filter. By locating the peaks of the filter output, one can roughly synchronize the received signal with the locally generated spreading signal. The code tracking

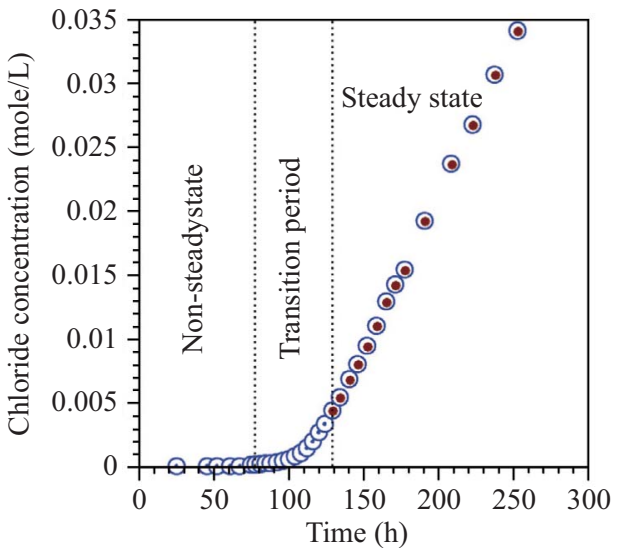

Fig. 4. The typical result (M45) of cumulative chloride concentration as a function of time.

is performed by using a modified noncoherent DLL, which fine-tunes the alignment between the received signal and the locally generated spreading signal. The operation of the modified noncoherent DLL will be explained later. With the aid of the synchronized timing, the DS/SS signal can be despreaded and demodulated properly. The adaptive DD-DFE following the DS/SS demodulator is used to cancel the residual intersymbol interference (ISI) in the demodulated signal. The channel decoder performs the $\mathrm{BCH}$ decoding to correct potential data errors caused by the channel impairments.

\section{RESULTS AND DISCUSSION}

\section{Breakthrough Time in ACMT}

In ACMT, the chloride concentration was determined from the solution in the anode cell, and the chloride concentration was the average of the results of three tests samples. The typical result of chloride concentration is plotted in Fig. 4 as a function of time. Fig. 4 shows that three stages exist, nonsteady state, transition period, and steady state with respect to the change of the chloride concentration. In the non-steadystate, the chloride ions are in the process of migrating through saturated pores in specimen and have not yet reached the anode cell. In the transition period, the first chloride ion starts to penetrate over through the specimen. The chloride-time curve of transition period is non-linear due to an uneven distribution of the chloride content in the specimen [8]. In the steady state, the flux of chloride ions passing through the specimen becomes constant.

The cumulative chloride concentrations in transition period of M35, M45, M55, and M65 are plotted in Fig. 5 as a function of time. Since the chloride concentration was not continually monitored and the duration of chloride ions penetrate over through specimen was not easy to determine, a regression line is carried out for the transition period portion of the chloride-time curve to determine the time-span for chloride ion penetration through specimen as: 


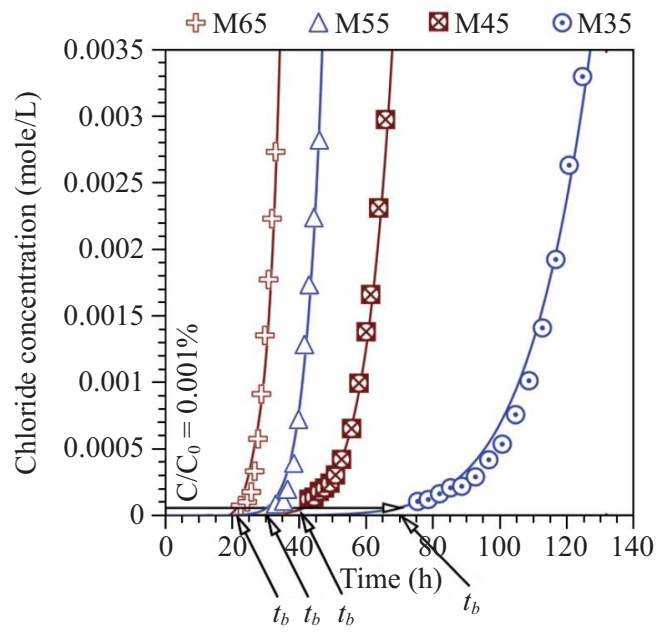

Fig. 5. The cumulative chloride concentrations in transition period of M35, M45, M55, and M65.

$$
C=a t^{b}, \text { for transition period, }
$$

where $C$ is chloride concentration gained from anode cell, a and $\mathrm{b}$ are experimental constants. The chloride concentration in anode cell of $C / C_{0}=0.01 \%\left(C_{0}\right.$ is the chloride concentration in cathodic cell) $[4,812]$ as shown in Fig. 5 is used as the average chloride front reached the surface of specimen in side of anode-cell. The Eq. (1) is fitted to the data of each specimen to determine the chloride-time curves in the transition period. Through regression analysis, the breakthrough time $\left(t_{b}\right)$ corresponding to the chloride concentration in the anode cell of $C / C_{0}=0.01 \%$ for each specimen is calculated and listed in Table 2. The breakthrough times of M35, M45, M55, and M65 are 73.1 h, 41.0 h, 29.8 h, and 20.7 h, respectively, and the breakthrough time decrease with the w/c ratios. In this study, five different accelerated migration times less than the breakthrough time $\left(t_{b}\right)$ of each mixes on a potential difference of 24 volt in Table 2 were used.

\section{The Non-Steady State Chloride Profile and the Charge Passed from ACMT}

\section{1) The Chloride Profile and Total Amount of Chloride}

In order to obtain the total amount of chloride in specimens after ACMT, the chloride penetration profile is used. The chloride profile is determined by collecting mortar powder samples at different depths after the end of chloride migration into specimen in ACMT.

The typical result of chloride-depth curve in non-steady state after the end of chloride migration into specimen in ACMT is provided in Fig. 6. The experimental data is fitted by using a non-linear regression analysis as:

$$
C_{c l}=C_{s} \cdot \exp \left(\frac{-x^{2}}{\delta \cdot t}\right)
$$

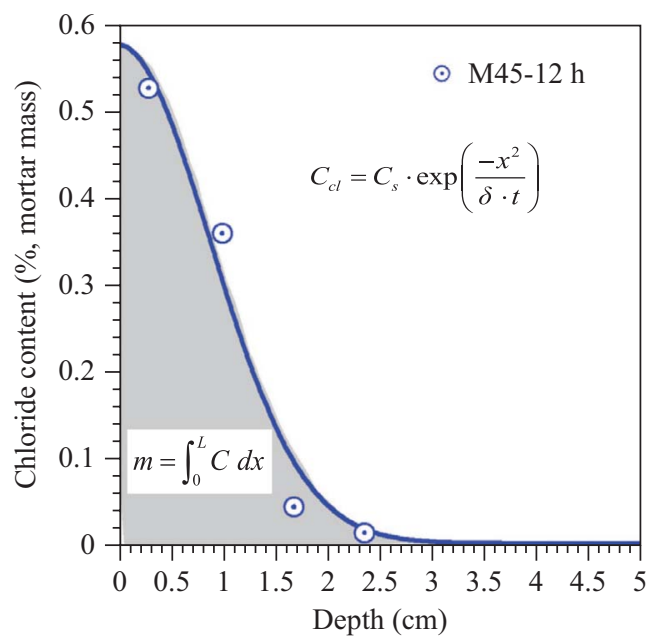

Fig. 6. The typical result of chloride-depth curve of non-steady state in ACMT.

where $C_{c l}$ is chloride content as a function of distant $x$, the surface chloride content $C_{s}$ is derived from Eq. (2) as $x=0, \delta$ is the chloride transport ability in specimen, and $t$ is the accelerated migration time. The fitting of Eq. (2) is conducted using a commercial curve fitting software program to search for a non-linear, least-square, best fit of the experimental data. The least-squares regression searches for the highest coefficient of determination $\left(R^{2}\right)$. The result of chloride-depth curve for M35, M45, M55, and M65 in non-steady state after the end of chloride migration into specimen in ACMT is provided in Fig. 7(a), (b), (c), and (d). The chloride transport ability $(\delta)$, the surface chloride content $\left(C_{s}\right)$, and the correlation coefficient $\left(R^{2}\right)$ for all mixes are listed in Table 3. By regression analysis, the coefficients of determination $R^{2}$ for all specimens are higher than 0.97. It appears that the correlates between experimental result and the model, Eq. (2), for all specimens are fairly good. In Table 3 , it can be seen that the surface chloride content $\left(C_{s}\right)$ increased slightly with the increasing accelerated migration time of all mixes. The results of the mixes test with various accelerated migration times indicate that there is no signification effect on the surface chloride content.

The total amount of diffusion substance in specimen as shown in Fig. 6 is determined by integrating the chloridedepth curve and calculated by:

$$
m=\int_{0}^{L} C d x, \quad t \geq 0,
$$

where $m$ is the total amount of chloride. From Eqs. (2) and (3), the total amount of chloride is written:

$$
m=\int_{0}^{L} C_{s} \cdot \exp \left(\frac{-x^{2}}{\delta \cdot t}\right) d x, \quad t \geq 0,
$$


Table 3. The surface chloride content $\left(C_{s}\right)$, and the chloride transport ability $(\delta)$ obtain from chloride profile of ACMT.

\begin{tabular}{|c|c|c|c|c|}
\hline Mix & $\begin{array}{c}\text { Accelerated } \\
\text { migration time (h) }\end{array}$ & $C_{s},(\%)$ & $\begin{array}{c}\delta, \\
\left(1 \times 10^{-5} \mathrm{~cm}^{2} \cdot s^{-1}\right)\end{array}$ & $R^{2}$ \\
\hline \multirow{4}{*}{ M35 } & 12 & 0.692 & 0.785 & 0.999 \\
& 24 & 0.707 & 1.712 & 0.980 \\
& 48 & 0.690 & 2.718 & 0.946 \\
& 72 & 0.760 & 3.483 & 0.955 \\
\hline \hline \multirow{4}{*}{ M45 } & 6 & 0.463 & 2.256 & 0.975 \\
& 12 & 0.573 & 3.653 & 0.970 \\
& 24 & 0.671 & 5.504 & 0.970 \\
& 36 & 0.705 & 6.774 & 0.962 \\
\hline \hline \multirow{3}{*}{ M55 } & 6 & 0.499 & 4.484 & 0.998 \\
& 12 & 0.559 & 5.902 & 0.989 \\
& 24 & 0.584 & 7.072 & 0.978 \\
& 3 & 0.609 & 10.265 & 0.985 \\
\hline \hline & 6 & 0.511 & 3.023 & 0.993 \\
& 12 & 0.469 & 5.810 & 0.990 \\
& 18 & 0.561 & 10.921 & 0.979 \\
& & 0.570 & 11.804 & 0.983 \\
\hline
\end{tabular}
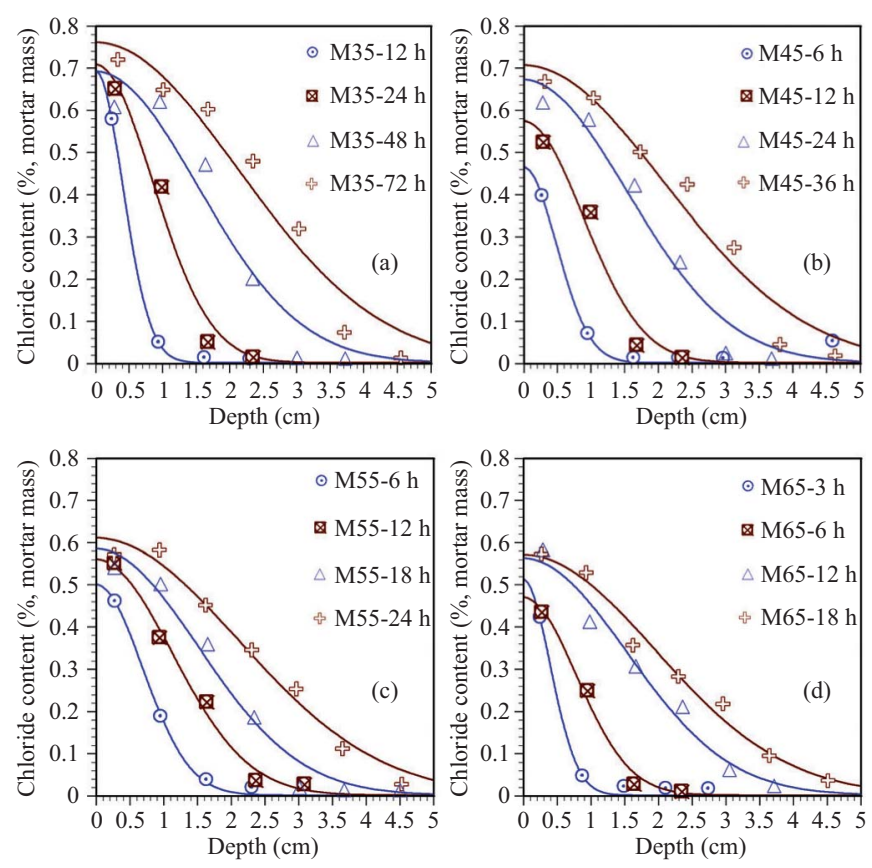

Fig. 7. Chloride profiles obtained after different migration time in ACMT with (a) $\mathrm{w} / \mathrm{c}=\mathbf{0 . 3 5}$, (b) w/c $=0.45$, (c) w/c $=0.55$, and (d) $\mathrm{w} / \mathrm{c}=$ 0.65.

The total amount of chloride $m$ obtained from the ACMT with five different of accelerated migration times calculated by using Eq. (4) for all mixes are listed in Table 4. A comparison of the total amount of chloride $(\mathrm{m})$ and the accelerated migration time $\left(t_{a}\right)$ are demonstrated in Fig. 8. In Fig. 8 shows
Table 4. Total amount of chloride and the total charge passed obtained from ACMT.

\begin{tabular}{|c|c|c|c|}
\hline Mix & $\begin{array}{c}\text { Accelerated } \\
\text { migration time, (h) }\end{array}$ & $m,(\% \cdot \mathrm{cm})$ & $Q$, (coulombs) \\
\hline \multirow{4}{*}{ M35 } & 12 & 0.352 & 2159 \\
\cline { 2 - 2 } & 24 & 0.755 & 4722 \\
\cline { 2 - 2 } & 48 & 1.324 & 9323 \\
\cline { 2 - 2 } M45 & 72 & 0.978 & 13336 \\
\cline { 2 - 2 } & 6 & 0.633 & 2021 \\
\cline { 2 - 2 } & 12 & 1.288 & 4058 \\
\hline \hline & 24 & 1.813 & 7836 \\
\cline { 2 - 2 } M55 & 36 & 0.434 & 11672 \\
\cline { 2 - 2 } & 12 & 0.787 & 2716 \\
\cline { 2 - 2 } & 18 & 1.102 & 5396 \\
\hline \hline & 24 & 1.574 & 8265 \\
\cline { 2 - 2 } M65 & 3 & 0.259 & 10991 \\
\cline { 2 - 2 } & 6 & 0.464 & 1952 \\
\cline { 2 - 2 } & 12 & 1.074 & 2913 \\
\hline
\end{tabular}

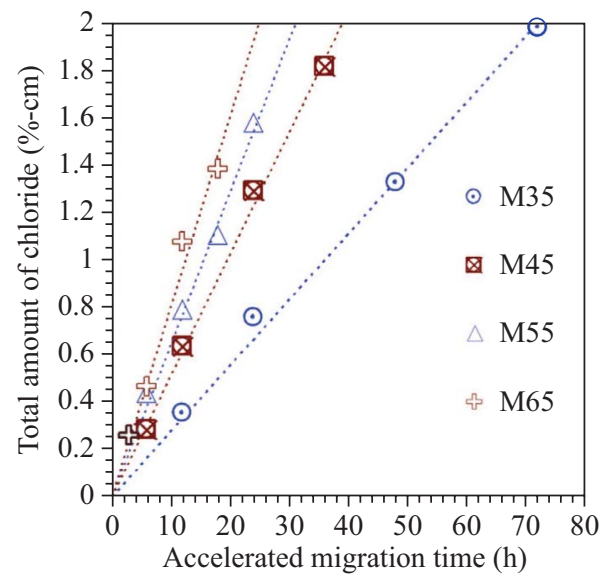

Fig. 8. A comparison of the total amount of chloride and the accelerated migration time.

that the total amount of chloride $(m)$ increase with the increasing accelerated migration time.

\section{2) Relation between the Charge Passed and the Total Amount of Chloride}

In an electrolyte solution of several ionic species, the total electrical current, $I$, is written:

$$
I=\sum_{i} I_{i}
$$

where $I_{i}$ is the electrical current resulting from the migration of the $i$ ion species. The current across the cells of ACMT was recorded by a data logger during the test. The charge passed, $Q$, is determined by integrating the current-time curve as: 


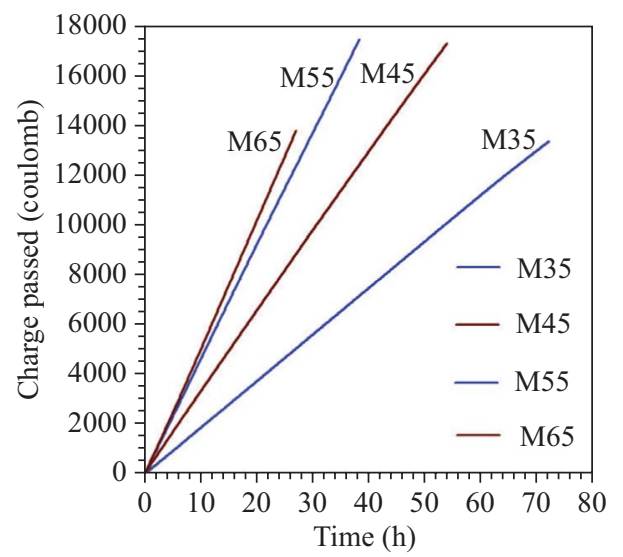

Fig. 9. The charge passed in function of time for all mixes.

$$
Q=\int I(t) d t
$$

where $I(t)$ is the time-dependent total electrical current and $t$ is the elapsed time. The charge passed obtained from the ACMT at four different accelerated migration times for all mixes are listed in Table 4. The charge passed in function of time for all mixes are presented in Fig. 9. The charge passed in Fig. 9 and the total amount of chloride in Fig. 8 increase with the increasing accelerated time. It can be realized from Figs. 8 and 9 that there is a relationship exist between the total amount of chloride $(m)$ and the charged passed $(Q)$ in the non-steady state.

The transference number of an ion in a given electrolyte solution is the fraction of the total electrical current carried in the solution by that ion [1]. Every specie in the electrolyte has a transference number, $t_{i}$, which must always be positive and between zero and one. According to the definition, the chloride transference number $\left(t_{c l}\right)$ can be calculated by the following equation as:

$$
t_{c l}=\frac{I_{c l}}{I}=\frac{Q_{c l}}{Q},
$$

where $I_{c l}$ is the electrical current carried in the solution by chloride ions, and $Q_{c l}$ is the charge passed carried by chloride ions.

According to the Faraday's results, the charge passed carried by chloride ions $\left(Q_{c l}\right)$ is determined by the mole number of chloride that pass through the circuit. By definition:

$$
Q_{c l}=N_{c l}\left|z_{c l}\right| F,
$$

where $z_{c l}$ is the electrical charge of chloride and $N_{c l}$ is the mole number of chloride in the anode cell in mole.

From Eqs. (7) and (8), the chloride transference number $t_{c l}$ can be written:

$$
t_{c l}=\frac{\left|z_{c l}\right| F N_{c l}}{Q},
$$

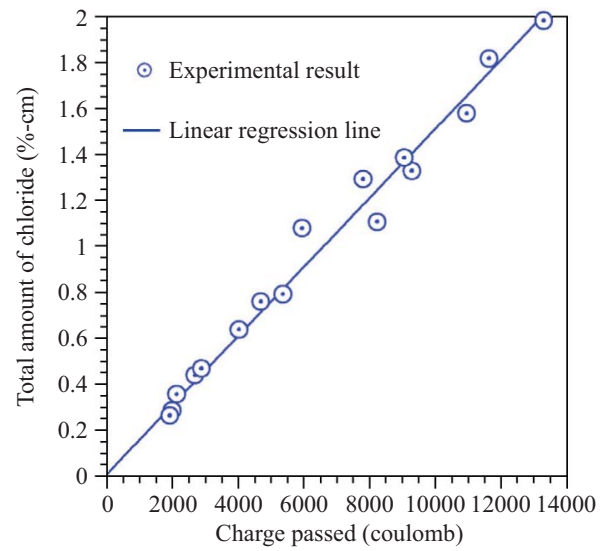

Fig. 10. The relationship between charge passed and the total amount of chloride obtained from ACMT.

and

$$
N_{c l}=\frac{t_{c l}}{\left|z_{c l}\right| F} Q
$$

From Eq. (10), when the chloride ions penetrate into specimen in non-steady state, the total amount of chloride $m$ is written:

$$
m=N_{c l} \cdot n_{c l}=\frac{t_{c l} n_{c l}}{\left|z_{c l}\right| F} Q,
$$

where the $n_{c l}$ is the atomic number of chloride $(35.5 \mathrm{~g} / \mathrm{mol})$. Eq. (11) shows that there is a relationship between the total amount of chloride and the charge passed in the non-steady state. Fig. 10 illustrates the relationship between the charge passed and the total amount of chloride obtained from ACMT, and a linear regression analysis is carried out. The empirical relationship between the total amount of chloride and the charge passed is statistically derived as:

$$
m=1.502 \times 10^{-4} Q,
$$

where $m$ is in $\%$-cm, and $Q$ is in Coulomb. The correlation coefficient $R^{2}$ for the model, Eq. (12), is 0.982 , which shows a fairly good linearity between the charge passed and the total amount of chloride. Comparing the linear regression results with Eq. (11), it indicates that the chloride transference number $\left(t_{c l}\right)$ is not significant different in this study. It appears that the total amount of chloride can be determined from the measurement of the charge passed.

\section{The Chloride Profile and the Total Amount of Chloride from Salt Ponding Test}

In the ponding test, specimens wee removed from salt ponding after the exposure period for $60,90,120$, and 150 days. 

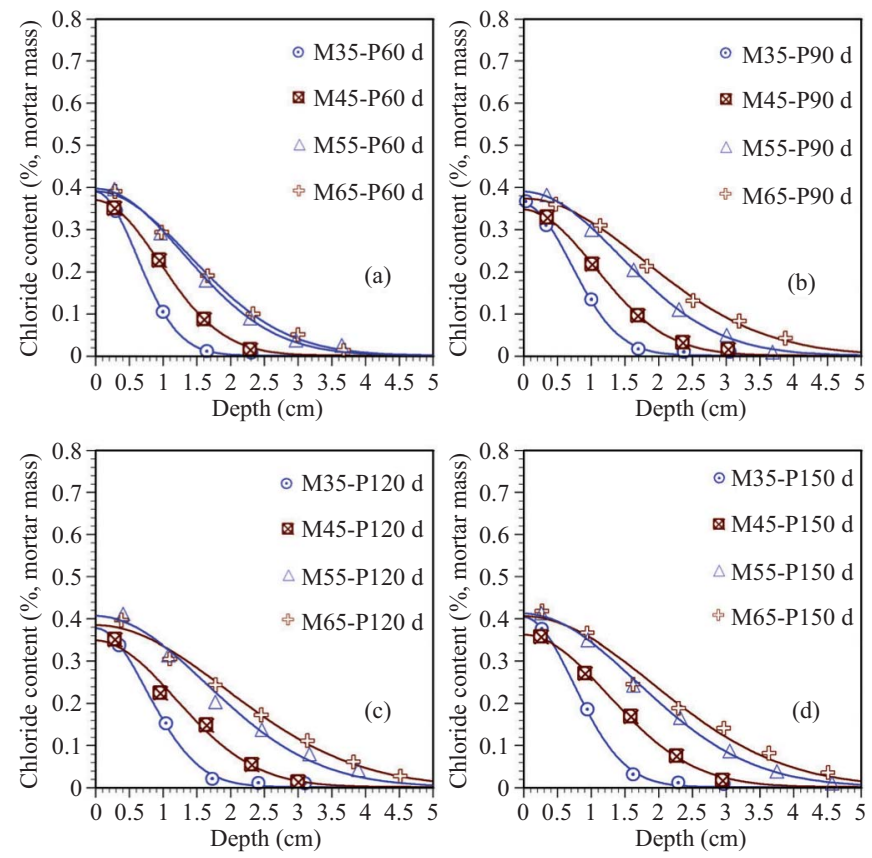

Fig. 11. Chloride profiles for all mixes in ponding test for (a) 60-day ponding time, (b) 90-day ponding time, (c) 120-day ponding time, and (d) 150-day ponding time.

The profiles of mixes M35, M45, M55, and M65 from the 60-dat, 90-day, 120-day, and 150-day chloride ponding test are shown in Fig. 11(a), (b), (c), and (d). The chloride content is expressed as the dry mass of specimen. The Eq. (2) is fitted to the data in Fig. 11 to obtain the chloride-depth curves, and the chloride transport ability $(\delta)$, the surface chloride content $\left(C_{s}\right)$, and the correlation coefficient $\left(R^{2}\right)$ for all mixes are listed in Table 5. By regression analysis, the coefficients of determination $R^{2}$ for all specimens are higher than 0.98 . It appears that the correlates between experimental data and the profiles of all mixes in Fig. 11 are fairly good. The total amount of chloride penetrated in specimen for all mixes, $m$, are calculated using Eq. (4), and are listed in Table 5.

\section{The Relation between Accelerated Chloride Migration Time and Ponding Time}

In the past, the 90-day salt ponding test has been conducted to evaluate the chloride diffusion characteristic of cementbased materials. The ponding test requires 90 days to obtain the chloride ions penetrate into the specimen. The disadvantage of ponding test is time-consuming. Therefore, ACMT method was used to accelerate the movement of chloride ions by the application of an external electrical field. In order to obtain the relationship between the accelerated chloride migration time in ACMT and the ponding time in salt ponding test, the total amount of chloride penetrated into specimen is used. The accelerated chloride migration time is determined based on the total amount of chloride $(m)$ obtained from ponding test and ACMT. The equivalent accelerated chloride migration time to the ponding time is obtained when the total amount of chloride is the same.
Table 5. Surface chloride content $\left(C_{s}\right)$, chloride transport ability $(\delta)$, and total amount of chloride obtain from the chloride profile of ponding test.

\begin{tabular}{|c|c|c|c|c|c|}
\hline Mix & $\begin{array}{c}\text { Ponding time, } \\
\text { (day) }\end{array}$ & $C_{s},(\%)$ & $\begin{array}{c}\delta, \\
\left(1 \times 10^{-5} \mathrm{~cm}^{2} \cdot s^{-1}\right)\end{array}$ & $R^{2}$ & $\begin{array}{c}m, \\
(\% \cdot \mathrm{cm})\end{array}$ \\
\hline \multirow{4}{*}{ M35 } & 60 & 0.388 & 1.491 & 0.999 & 0.302 \\
\hline & 90 & 0.358 & 1.296 & 0.998 & 0.317 \\
\hline & 120 & 0.376 & 1.138 & 0.997 & 0.360 \\
\hline & 150 & 0.403 & 0.871 & 0.998 & 0.378 \\
\hline \multirow{4}{*}{ M45 } & 60 & 0.367 & 3.489 & 0.999 & 0.436 \\
\hline & 90 & 0.345 & 2.930 & 0.999 & 0.460 \\
\hline & 120 & 0.380 & 3.401 & 0.999 & 0.517 \\
\hline & 150 & 0.360 & 2.463 & 0.998 & 0.568 \\
\hline \multirow{4}{*}{ M55 } & 60 & 0.395 & 6.754 & 0.996 & 0.655 \\
\hline & 90 & 0.379 & 4.035 & 0.991 & 0.701 \\
\hline & 120 & 0.404 & 5.233 & 0.986 & 0.831 \\
\hline & 150 & 0.410 & 4.409 & 0.997 & 0.863 \\
\hline \multirow{4}{*}{ M65 } & 60 & 0.389 & 7.668 & 0.997 & 0.685 \\
\hline & 90 & 0.372 & 8.239 & 0.997 & 0.829 \\
\hline & 120 & 0.383 & 7.248 & 0.991 & 0.920 \\
\hline & 150 & 0.404 & 5.697 & 0.980 & 0.960 \\
\hline
\end{tabular}

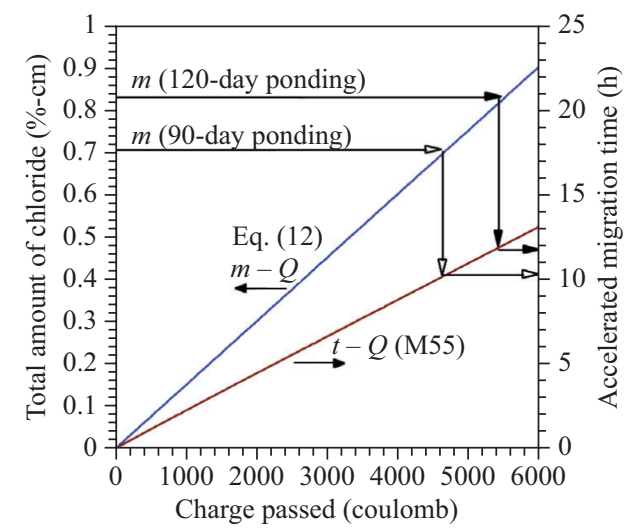

Fig. 12. The $m-Q$ curve and the $t-Q$ curve obtained from ACMT. An example is presented to obtain the accelerated migration time in ACMT from the total amount of chlorides from salt ponding test.

Both of the $m-Q$ curve (from Eq. (12)) and the $t-Q$ curve obtained from ACMT are shown in Fig. 12. Examples of the total amount of chlorides penetrated into specimen from the 90-day and 120-day salt ponding test for M55 as shown in Fig. 12 are 0.701 and $0.831 \%-\mathrm{cm}$. The required charges are 4571 and 6066 coulomb in ACMT, and the equivalent accelerated chloride migration times are 10.0 and $11.9 \mathrm{~h}$. The required charge and the equivalent accelerated chloride migration time for all mixes from different ponding time are listed in Table 6. The test result and model presented in this study can be used to obtain the relationship between the accelerated chloride migration time in ACMT and the ponding time in salt ponding test. The surface chloride content may not consider in the 
Table 6. The required charge passed and the equivalent accelerated chloride migration time for all mixes from different ponding time.

\begin{tabular}{|c|c|c|c|c|}
\hline \multirow{2}{*}{$\begin{array}{l}\text { Ponding } \\
\text { time } \\
\text { (day) }\end{array}$} & \multirow[t]{2}{*}{ Mix } & \multirow{2}{*}{$\begin{array}{c}\text { Require } \\
\text { charge } \\
\text { (coulomb) }\end{array}$} & \multicolumn{2}{|c|}{$\begin{array}{l}\text { The equivalent accelerated } \\
\text { chloride migratin time (h) }\end{array}$} \\
\hline & & & & Avg. \\
\hline \multirow{4}{*}{60} & M35 & 1969 & 10.3 & \multirow[b]{4}{*}{9.3} \\
\hline & M45 & 2843 & 8.8 & \\
\hline & M55 & 4274 & 9.4 & \\
\hline & M65 & 4466 & 8.8 & \\
\hline \multirow{4}{*}{90} & M35 & 2067 & 10.9 & \multirow[b]{4}{*}{10.2} \\
\hline & M45 & 2999 & 9.3 & \\
\hline & M55 & 4571 & 10.0 & \\
\hline & M65 & 5405 & 10.7 & \\
\hline \multirow{4}{*}{120} & M35 & 2347 & 12.3 & \multirow[b]{4}{*}{11.6} \\
\hline & M45 & 3371 & 10.4 & \\
\hline & M55 & 5418 & 11.9 & \\
\hline & M65 & 5999 & 11.9 & \\
\hline \multirow{4}{*}{150} & M35 & 2465 & 13.0 & \multirow[b]{4}{*}{12.3} \\
\hline & M45 & 3703 & 11.5 & \\
\hline & M55 & 5627 & 12.3 & \\
\hline & M65 & 6259 & 12.4 & \\
\hline
\end{tabular}

result presented. The comparison between the ACMT and ponding test determined total amount of chloride provides a direction to obtain the relationship between the accelerated chloride migration time in ACMT and the ponding time in salt ponding test. The accelerated migration time in ACMT needed for obtaining consistent values of the total amount of chloride for cement-based materials equilibrated with 60-day, 90-day, 120-day, and 150-day ponding time are approximately $9 \mathrm{~h}, 10 \mathrm{~h}, 11 \mathrm{~h}$, and $12 \mathrm{~h}$, respectively.

\section{CONCLUSION}

The chloride content at various depths in mortar was measured after the ACMT and ponding test. The charge passed was measured after the ACMT. The conclusions derived from the experimental investigation and regression analysis are presented below.

1. In ACMT, the charge passed and the total amount of chloride increase with the increasing accelerated migration time.

2. The charge passed and the total amount of chloride penetrated in mortar is linearly correlated after ACMT. The total amount of chloride can be determined from the measurement of the charge passed. This method provides a less expensive and easy way to obtain the total amount of chloride penetrated in the non-steady state.

3. The accelerated migration time in ACMT needed for obtaining consistent values of the total amount of chloride for cement-based materials equilibrated with 60-day, 90-day, 120-day, and 150-day ponding time are approximately $9 \mathrm{~h}$, $10 \mathrm{~h}, 11 \mathrm{~h}$, and $12 \mathrm{~h}$, respectively. The ACMT provides a method to avoid the disadvantage of ponding test for the time-consuming.

This is an initial work on the relationship between accelerated chloride migration time and the ponding time. The further study is needed to obtain result at longer migration and ponding time, with different concrete compositions, and also to account for the surface chloride content or chloride penetration depth.

\section{ACKNOWLEDGMENTS}

The financial support of National Science Council, ROC, under the grant NSC 96-2628-E-019-029-MY3 and NSC 98-2221-E-019-048-MY3 is gratefully appreciated.

\section{REFERENCES}

1. Andrade, C., "Calculation of chloride diffusion coefficients in concrete from ionic migration measurements," Cement and Concrete Research, Vol. 23, No. 3, pp. 724-742 (1993).

2. Andrade, C. and Whiting, D., "A comparison of chloride ion diffusion coefficients derived from concentration gradients and non-steady state accelerated ionic migration," Materials and Structures, Vol. 29, No. 192, pp. 476-484 (1996).

3. Dhir, R. K. and Byars, E. A., "PFA concrete: chloride diffusion rates," Magazine of Concrete Research, Vol. 45, No. 162, pp. 1-9 (1993).

4. Halamickova, P., Detwiler, R. J., Bentz, D. P., and Garboczi, E. J., "Water permeability and chloride ion diffusion in portland cement mortars: relationship to sand content and critical pore diameter," Cement and Concrete Research, Vol. 25, No. 4, pp. 790-802 (1995).

5. Li, Z., Peng, J., and Ma, B., "Investigation of chloride diffusion for highperformance concrete containing fly ash, microsilica and chemical admixtures," ACI material Journal, Vol. 96, No. 3, pp. 391-396 (1999).

6. McGrath, P. F. and Hooton, R. D., "Re-evaluation of the AASHTO T259 90-day salt ponding test," Cement and Concrete Research, Vol. 29, No. 8, pp. 1239-1248 (1999).

7. Page, C. L., Short, N. R., and Tarros, A. E. L., "Diffusion of chloride ions in hardened cement pastes," Cement and Concrete Research, Vol. 11, No. 3, pp. 395-406 (1981).

8. Tong, L. and Gjorv, O. E., "Chloride diffusivity based on migration testing," Cement and Concrete Research, Vol. 31, No. 7, pp. 973-982 (2001).

9. Whiting, D., "Rapid measurements of chloride permeability of concrete," Public Roads, Vol. 45, No. 3, pp. 101-112 (1981).

10. Yang, C. C., "The relationship between migration coefficient of chloride ions for concrete and charge passed in steady state using the accelerated chloride migration test," ACI Materials Journal, Vol. 101, No. 2, pp. 124-130 (2004).

11. Yang, C. C. and Chiang, S. C., "A rapid Method for determination of the chloride migration coefficient in concrete using electrical field," Journal of ASTM International, Vol. 5, No. 4, Paper ID JAI101409 (2008).

12. Yang, C. C., Chiang, S. C., and Wang, L. C., "Estimation of the chloride diffusion from migration test using electrical current," Construction and Building Materials, Vol. 21, No. 7, pp. 1560-1567 (2007).

13. Yang, C. C. and Cho, S. W., "The relationship between chloride migration rate for concrete and electrical current in steady state using the accelerated chloride migration test," Material and Structure, Vol. 37, No. 271, pp. 456-463 (2004). 